\title{
The effect of etanercept on traditional metabolic risk factors for cardiovascular disease in patients with rheumatoid arthritis
}

\author{
Atul Deodhar ${ }^{1} \cdot$ Bojena Bitman $^{2} \cdot$ Yue Yang $^{2} \cdot$ David H Collier $^{2}$
}

Received: 15 June 2016 /Revised: 14 September 2016 / Accepted: 17 September 2016/Published online: 5 October 2016

(C) The Author(s) 2016. This article is published with open access at Springerlink.com

\begin{abstract}
Patients with rheumatoid arthritis (RA) are at an increased risk of cardiovascular disease (CVD). Treatment with tumor necrosis factor inhibitors improves both joint symptoms associated with RA and also CVD risk. This exploratory analysis of a phase 4 study evaluated changes in metabolic risk factors in patients with RA treated with etanercept. Metabolic analytes were measured at baseline, week 12 , and week 24 in patients enrolled in a randomized, double-blind, placebo-controlled study to evaluate the efficacy and safety of etanercept in moderately active RA. Patients received either placebo or etanercept $50 \mathrm{mg}$ every week $(\mathrm{QW})$ for 12 weeks, after which all patients received etanercept $50 \mathrm{mg}$ QW through week 24. Levels of metabolic analytes were assessed in all patients, including patients with diabetes and hyperlipidemia, and described descriptively. A total of 210 patients were randomized, 104 to placebo and 106 to etanercept. There were no significant changes in metabolic risk factors from baseline to week 12 or 24 in all patients. Levels of metabolic analytes were similar in patients with diabetes and hyperlipidemia, with some exceptions; fasting glucose and fasting insulin decreased through week 12, and hemoglobin A1C decreased slightly through week 24 in patients with diabetes. Treatment with etanercept did not adversely affect levels of metabolic risk factors for CVD in patients with RA.
\end{abstract}

Atul Deodhar

deodhara@ohsu.edu

1 Division of Arthritis and Rheumatic Diseases (OP09), Oregon Health and Science University, Portland, OR 97239, USA

2 Amgen Inc., 1 Amgen Center Drive, Thousand Oaks, CA 91320, USA
Keywords Cardiovascular disease $\cdot$ Rheumatoid arthritis Tumor necrosis factor inhibitor

\section{Introduction}

It is well documented that patients with rheumatoid arthritis (RA) are at an increased risk of cardiovascular disease (CVD) and experience higher rates of cardiovascular (CV) morbidity and mortality than the general population [1-4]. While traditional CVD risk factors - including cholesterol levels - may contribute to this heightened risk in patients with RA, they do not completely account for the increased incidence of $\mathrm{CV}$ events $[5,6]$. In addition to traditional CVD risk factors, the systemic inflammation associated with RA also plays a role in increasing CVD risk in patients [7]. Decreasing inflammation is thought to decrease CV morbidity and mortality in patients with RA [8]. Tumor necrosis factor inhibitor (TNFi) therapy, in particular, has been shown to improve both RA symptoms and CVD risk and reduce CV morbidity and mortality $[9,10]$. In this study, we measured the levels of selected metabolic analytes in patients with RA who received treatment with etanercept to further understand the effect of TNFi therapy on traditional CVD risk factors.

\section{Materials and methods}

\section{Study design}

The evaluation of CVD risk factors was an exploratory endpoint in a phase 4, prospective, randomized, double-blind, placebo-controlled study (NCT01313208) to evaluate the efficacy and safety of etanercept in patients with moderately active RA despite disease-modifying anti-rheumatic drug 
(DMARD) therapy. Patients were randomized 1:1 to receive $50 \mathrm{mg}$ etanercept or placebo every week (QW) for 12 weeks, stratified by current methotrexate (MTX) use (yes/no). At week 12, all patients received $50 \mathrm{mg}$ etanercept QW for another 12 weeks.

\section{Patients}

Eligibility criteria have been previously published [11]. In particular, patients were required to have moderately active RA, as defined by their disease activity score based on 28 joints (DAS28) with C-reactive protein (CRP) as the indicator of inflammation $(3.2<$ DAS28-CRP $\leq 5.1)$.

\section{Subpopulations of interest}

Patients were further categorized based on diabetes and hyperlipidemia. Patients with diabetes were defined as those with a current history of diabetes (stop date in medical history missing or after enrollment date), and/or taking insulin, and/or taking oral anti-diabetics. Patients with hyperlipidemia were defined as those with a current history of hyperlipidemia or hypercholesterolemia (stop date in medical history missing or after enrollment date) and/or taking statins.

\section{Objective}

The objective of this study was to evaluate changes in metabolic CVD risk factors in patients with moderately active RA treated with etanercept.

\section{Outcomes}

The metabolic analytes measured in this study were fasting glucose, fasting insulin, hemoglobin A1C, total cholesterol, high-density lipoprotein (HDL), low-density lipoprotein (LDL), triglycerides, apolipoprotein A1, apolipoprotein B, adiponectin, leptin, and plasma $\mathrm{N}$-terminal pro b-type natriuretic peptide (NT-proBNP). Shifts in grade (low, normal, high) for each analyte from baseline to week 24 were also measured.

\section{Statistical analyses}

Baseline demographics, disease characteristics, and metabolic parameters were summarized descriptively for the overall study population and diabetic and hyperlipidemic subpopulations by treatment groups and time points. Changes in metabolic parameters over time during the study are also displayed graphically.

\section{Human rights}

The study protocol and informed consent form were approved by the applicable Independent Ethics Committee (IEC) or Institutional Review Board (IRB). Patients were informed of all aspects of the study, and the forms were obtained before patients entered the study.

\section{Results}

\section{Demographic and clinical characteristics at baseline}

A total of 210 patients were enrolled in this study. During the first 12 weeks, 104 patients were randomized to placebo and 106 patients were randomized to etanercept (Table 1). The double-blind phase was completed by $95 \%$ of patients: $94 \%$ placebo and $95 \%$ etanercept (Fig. 1). The open-label phase was completed by $91 \%$ of patients: $89 \%$ placeboetanercept and $93 \%$ etanercept-etanercept. Overall, the patients had a mean (standard deviation [SD]) age of 56 (12) years, were $77 \%$ female, were $87 \%$ white, had a mean (SD) RA duration of 8 (10) years, and had a mean (SD) disease severity (as measured by DAS28-CRP) of $4.9(0.8)$ (Table 1). There were $14 \%$ of patients with a medical history of diabetes and $30 \%$ with a medical history of hyperlipidemia or hypercholesterolemia. There were $22 \%$ of patients receiving statins, $11 \%$ anti-diabetic oral agents, $3 \%$ insulin, and $52 \%$ prednisone.

\section{Changes in metabolic analytes}

Levels of CRP decreased in the overall study population by week 24, but there were no significant changes in any other metabolic analytes measured from baseline to weeks 12 and 24 in all patients (Table 2). There were rare elevations in liver function tests and none greater than three times normal.

The metabolic analytes in patients with diabetes and hyperlipidemia did not change substantially from baseline to week 12 or 24 and were similar to those in the total study population, with some exceptions (Table 2 and Fig. 2). In patients with diabetes, fasting glucose decreased, HDL increased, and LDL decreased through week 12 in those receiving etanercept. In both subpopulations, fasting insulin decreased through week 12 and hemoglobin A1C decreased slightly through week 24. In addition, apolipoprotein A1 increased (with the exception of patients with diabetes receiving placeboetanercept) and adiponectin increased slightly through week 24; leptin and apolipoprotein B did not change. Patients at a higher CVD risk experienced no or minimal changes in metabolic analytes from baseline to weeks 12 and 24. All changes that patients did experience were neither statistically nor clinically significant. Metabolic analytes were also compared 
Table 1 Demographic and clinical characteristics at baseline

\begin{tabular}{|c|c|c|c|}
\hline Characteristic & $\begin{array}{l}\text { Placebo-etanercept } \\
n=104\end{array}$ & $\begin{array}{l}\text { Etanercept-etanercept } \\
n=106\end{array}$ & $\begin{array}{l}\text { Total } \\
n=210\end{array}$ \\
\hline Sex (female), $n(\%)$ & $86(82.7)$ & $75(70.8)$ & $161(76.7)$ \\
\hline Race (white), $n(\%)$ & $90(86.5)$ & $93(87.7)$ & $183(87.1)$ \\
\hline Age (years), mean (SD) & $55.5(12.8)$ & $56.5(12.1)$ & $56.0(12.4)$ \\
\hline DAS28-CRP, mean (SD) & $4.9(0.8)$ & $4.9(0.7)$ & $4.9(0.8)$ \\
\hline CRP (mg/L), mean (SD) & $9.4(16.3)$ & $7.6(11.8)$ & $8.5(14.2)$ \\
\hline ESR $(\mathrm{mm} / \mathrm{h})$, mean $(\mathrm{SD})$ & $30.8(23.5)$ & $30.3(22.8)$ & $30.6(23.1)$ \\
\hline \multicolumn{4}{|l|}{ Tobacco, $n(\%)$} \\
\hline Never & $49(47.1)$ & $54(50.9)$ & $103(49.0)$ \\
\hline Former & $35(33.7)$ & $34(32.1)$ & $69(32.9)$ \\
\hline Current & $20(19.2)$ & $18(17.0)$ & $38(18.1)$ \\
\hline RA duration (years), mean (SD) & $7.4(8.1)$ & $8.3(11.2)$ & $7.8(9.8)$ \\
\hline RA medication history, $n(\%)$ & $103(99.0)$ & $106(100.0)$ & $209(99.5)$ \\
\hline DMARDs (nonbiologic) & $103(99.0)$ & $105(99.1)$ & $208(99.0)$ \\
\hline NSAIDs & $70(67.3)$ & $75(70.8)$ & $145(69.0)$ \\
\hline Corticosteroids & $68(65.4)$ & $73(68.9)$ & $141(67.1)$ \\
\hline Analgesics & $44(42.3)$ & $38(35.8)$ & $82(39.0)$ \\
\hline Biologics & $10(9.6)$ & $10(9.4)$ & $20(9.5)$ \\
\hline Other & $1(1.0)$ & $0(0.0)$ & $1(0.5)$ \\
\hline Type 2 diabetes mellitus ${ }^{\mathrm{a}}, n(\%)$ & $12(11.5)$ & $17(16.0)$ & $29(13.8)$ \\
\hline Hyperlipidemia $^{\mathrm{b}}, n(\%)$ & $30(28.8)$ & $33(31.1)$ & $63(30.0)$ \\
\hline \multicolumn{4}{|l|}{ Other medication history, $n(\%)$} \\
\hline Statin & $21(20.2)$ & $26(24.5)$ & $47(22.4)$ \\
\hline Insulin & $2(1.9)$ & $4(3.8)$ & $6(2.9)$ \\
\hline Oral anti-diabetic & $10(9.6)$ & $12(11.3)$ & $22(10.5)$ \\
\hline Prednisone & $53(51.0)$ & $57(53.8)$ & $110(52.4)$ \\
\hline
\end{tabular}

$S D$ standard deviation, $D A S 28$ disease activity score based on 28 joints, $C R P$ C-reactive protein, $E S R$ erythrocyte sedimentation rate, $R A$ rheumatoid arthritis, DMARD disease-modifying anti-rheumatic drug, NSAID nonsteroidal anti-inflammatory drug

${ }^{\text {a }}$ Patients with type 2 diabetes mellitus were defined as those with a current history of diabetes (stop date in medical history missing or after enrollment date), and/or taking insulin, and/or taking oral anti-diabetics

${ }^{\mathrm{b}}$ Patients with hyperlipidemia were defined as those with a current history of hyperlipidemia or hypercholesterolemia (stop date in medical history missing or after enrollment date) and/or receiving statins between patients receiving concurrent nonsteroidal antiinflammatory drugs and those who were not, among the total study population, patients with diabetes, and patients with hyperlipidemia; responses were similar between groups (data not shown).

\section{Shifts in grade for analytes}

For the majority of patients, all metabolic analytes were in the normal range at baseline. The majority of patients completed the study week 24 at a normal grade for each analyte measured. Fewer than $25 \%$ of patients in either treatment group experienced a shift in grade between baseline and week 24 for each metabolic analyte measured. Among those who did experience a shift in grade, patients were fairly evenly divided between those who improved in grade and those who worsened.

\section{Discussion}

Treatment with etanercept did not adversely or positively affect the levels of traditional metabolic CVD risk factors in patients with RA. There were no significant changes in these metabolic analytes despite improvements in RA activity parameters, as indicated by decreases in CRP in both groups on etanercept by week 24. Previously reported improvements in CVD risk associated with TNFi therapy may stem from changes in other factors such as decrease in systemic inflammation. Results seen in patients with diabetes and 


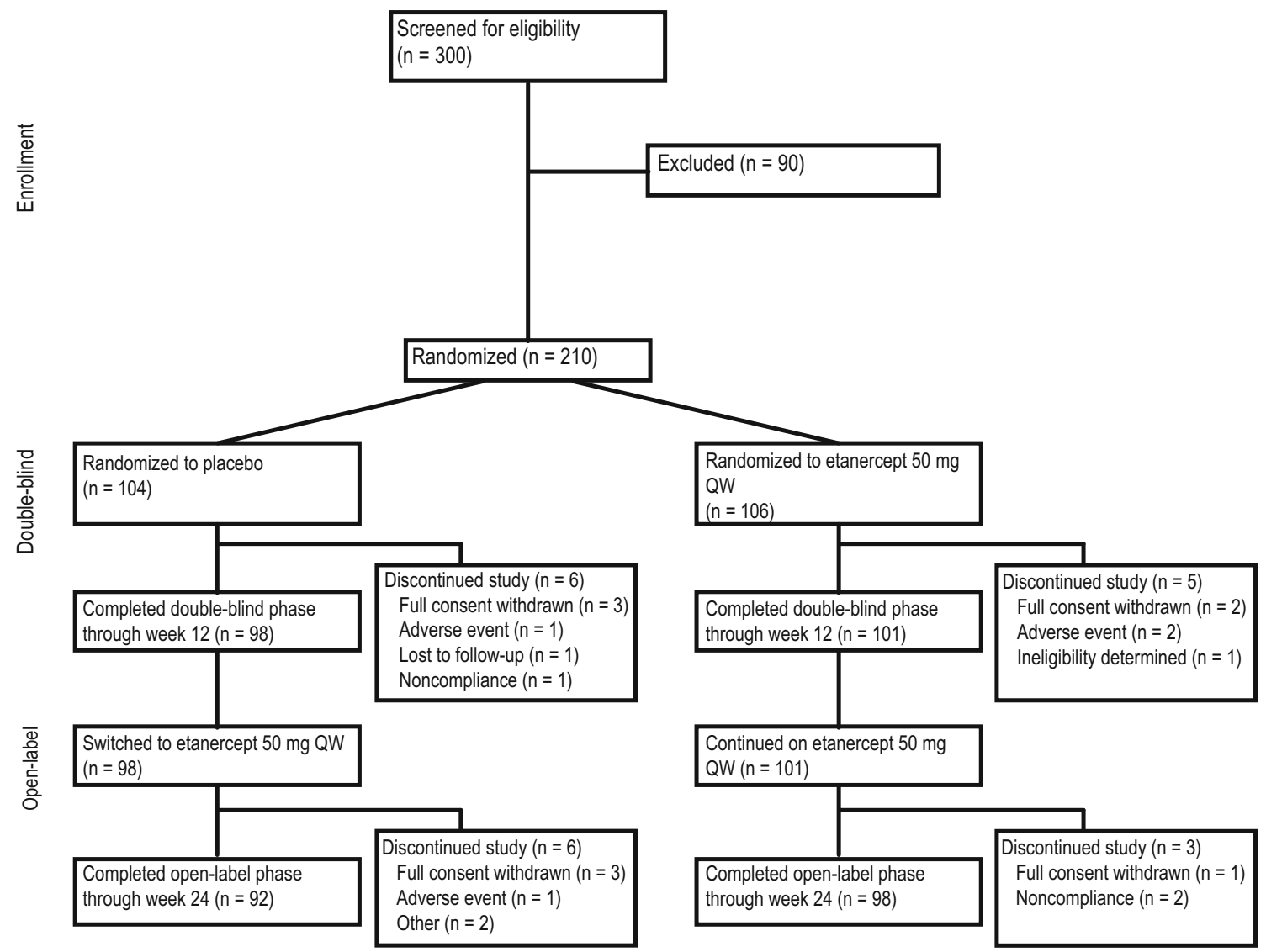

Fig. 1 Patient disposition. The flow of patients from screening through week 24 of the study. QW every week

hyperlipidemia demonstrated that there were no changes in traditional metabolic CVD risk factors, even in patients who were at a heightened risk of CVD.

Patients with RA exhibit a lipid paradox, in which patients with untreated RA have lower total cholesterol, HDL, and LDL than the general population, in which these lipid parameters are conventionally at elevated levels when patients are at a higher risk for CVD $[5,12,13]$. A potential explanation is that higher levels of CRP have been shown to decrease levels of lipids [6]. Elevated levels of CRP have been shown to independently correlate with increased CVD risk; a previous study has shown that elevated CRP was associated with an up to threefold increase in the risk of a heart attack [14]. Treatment to control RA subsequently results in an increase in total cholesterol, HDL, and LDL, without a concomitant increase in CVD risk; and in some cases even a decrease in CVD risk [6, 12, 13, 15, 16]. In our study, patients did not experience any change in levels of lipids, similar to some previous studies $[15,17]$.

Treatment with TNFi therapy, including etanercept, has been shown to lower CVD risk in patients with RA [18-20]. Based on analyses in this study and others, the reduction in CVD risk in patients with RA cannot be fully explained by changes in traditional metabolic risk factors. Managing RA symptoms and reducing inflammation in these patients appears to play a key role to decreasing CVD risk [8]. One study has even shown that the degree to which TNFi therapy reduces disease activity is proportional to the reduction in CVD risk [19]. One possible explanation behind the beneficial effect of TNFi therapy on CVD risk may relate a reduction in overall inflammation to a reduction in aortic inflammation. Findings from Maki-Petaja and colleagues demonstrated that TNFi therapy reduced aortic inflammation in patients with RA after 8 weeks of treatment, and this effect correlated with a decrease in aortic stiffness [21]. This study provides further evidence that the main effect of TNFi therapy is on inflammation, which can directly decrease inflammation in the aorta, preventing plaque formation or progression. Similar to reports on TNFi therapy, other biologics (e.g., interleukin-6 receptor inhibitor) also worsen the lipid profile with no worsening of CVD risk [22, 23].

The well-established benefit of TNFi therapy on CVD risk in patients with RA may also not be apparent in the short term. Recent work by Charles-Schoeman and colleagues demonstrated that patients with early RA in the treatment of early aggressive rheumatoid arthritis (TEAR) trial experienced increases in lipids (total cholesterol, LDL, and HDL) through 24 weeks of treatment with etanercept; these levels began to decrease by 48 weeks of treatment, with statistically significant reductions by week 102 compared with week 24 [24]. 
Table 2 Summary of analytes in all patients, patients with diabetes, and patients with hyperlipidemia

\begin{tabular}{|c|c|c|c|c|c|c|c|}
\hline \multirow[t]{2}{*}{ Analyte, mean (SD) } & \multirow[t]{2}{*}{ Visit } & \multicolumn{2}{|l|}{ All } & \multicolumn{2}{|l|}{ Diabetes } & \multicolumn{2}{|l|}{ Hyperlipidemia } \\
\hline & & $\begin{array}{l}\text { PBO-ETN } \\
n=104\end{array}$ & $\begin{array}{l}\text { ETN-ETN } \\
n=106\end{array}$ & $\begin{array}{l}\text { PBO-ETN } \\
n=12\end{array}$ & $\begin{array}{l}\text { ETN-ETN } \\
n=17\end{array}$ & $\begin{array}{l}\text { PBO-ETN } \\
n=30\end{array}$ & $\begin{array}{l}\text { ETN-ETN } \\
n=33\end{array}$ \\
\hline \multirow[t]{3}{*}{ Fasting glucose, $\mathrm{mg} / \mathrm{dL}$} & Baseline & $99.0(30.7)$ & $98.6(30.3)$ & $143.0(69.2)$ & $142.3(53.1)$ & $113.8(46.2)$ & $111.4(43.5)$ \\
\hline & Week 12 & $95.9(22.3)$ & $97.3(26.6)$ & $127.3(42.4)$ & $133.1(47.1)$ & $104.3(32.1)$ & $105.9(29.3)$ \\
\hline & Week 24 & $101.0(22.8)$ & $100.1(24.0)$ & $134.8(35.9)$ & $138.4(35.8)$ & $105.3(26.0)$ & $107.6(17.3)$ \\
\hline \multirow[t]{3}{*}{ Fasting insulin, mIU/L } & Baseline & $14.3(17.6)$ & $16.0(34.9)$ & $24.4(18.3)$ & $40.3(79.5)$ & $22.4(28.5)$ & $26.8(60.6)$ \\
\hline & Week 12 & $15.3(22.4)$ & $13.2(13.5)$ & $20.2(15.0)$ & $16.1(21.5)$ & $18.0(16.2)$ & $17.7(17.3)$ \\
\hline & Week 24 & $15.0(18.4)$ & $12.0(12.1)$ & $23.0(22.7)$ & $14.8(14.0)$ & $14.6(11.9)$ & $14.4(12.8)$ \\
\hline \multirow[t]{3}{*}{ Hemoglobin A1C, \% } & Baseline & $5.7(0.9)$ & $5.7(0.7)$ & $7.2(1.9)$ & $6.7(1.2)$ & $6.1(1.4)$ & $6.1(1.0)$ \\
\hline & Week 12 & $5.7(0.9)$ & $5.6(0.6)$ & $7.0(2.1)$ & $6.7(0.8)$ & $5.9(1.3)$ & $6.0(0.8)$ \\
\hline & Week 24 & $5.6(0.9)$ & $5.6(0.6)$ & $6.8(1.9)$ & $6.5(0.8)$ & $5.9(1.2)$ & $5.8(0.6)$ \\
\hline \multirow[t]{3}{*}{ Total cholesterol, mg/dL } & Baseline & $195.2(44.2)$ & $186.6(37.1)$ & $204.0(32.9)$ & $171.9(36.6)$ & $205.1(55.1)$ & $181.6(42.5)$ \\
\hline & Week 12 & $190.9(40.7)$ & $184.8(37.4)$ & $205.6(36.2)$ & $170.0(33.7)$ & $190.7(44.2)$ & $182.6(44.5)$ \\
\hline & Week 24 & $197.0(41.7)$ & $191.1(39.6)$ & $185.5(32.4)$ & $179.9(37.3)$ & $192.8(44.4)$ & $190.5(43.2)$ \\
\hline \multirow[t]{3}{*}{$\mathrm{HDL}, \mathrm{mg} / \mathrm{dL}$} & Baseline & $62.0(18.1)$ & $62.1(21.7)$ & $52.6(13.2)$ & $57.8(17.1)$ & $57.4(12.3)$ & $58.5(18.0)$ \\
\hline & Week 12 & $60.5(17.1)$ & $61.6(18.3)$ & $54.7(13.6)$ & $61.9(19.5)$ & $56.9(14.0)$ & $61.4(19.1)$ \\
\hline & Week 24 & $62.1(18.5)$ & $62.2(22.9)$ & $52.1(14.5)$ & $60.6(15.5)$ & $56.0(13.8)$ & $62.1(18.4)$ \\
\hline \multirow[t]{3}{*}{$\mathrm{LDL}, \mathrm{mg} / \mathrm{dL}$} & Baseline & $105.6(36.3)$ & $97.8(30.0)$ & $118.4(26.9)$ & $81.8(29.5)$ & $109.0(40.7)$ & $92.7(37.2)$ \\
\hline & Week 12 & $103.2(35.4)$ & $96.9(33.2)$ & $112.1(32.3)$ & $79.3(31.5)$ & $102.2(38.2)$ & $90.3(39.3)$ \\
\hline & Week 24 & $105.5(35.4)$ & $101.7(31.0)$ & $101.9(89.1)$ & $89.1(31.5)$ & $99.0(34.3)$ & $100.0(33.3)$ \\
\hline \multirow[t]{3}{*}{ Triglycerides, mg/dL } & Baseline & $135.2(91.6)$ & $133.1(80.1)$ & $164.7(68.6)$ & $163.2(91.6)$ & $183.8(134.1)$ & $154.2(78.0)$ \\
\hline & Week 12 & $139.2(85.5)$ & $131.8(69.4)$ & $221.9(170.3)$ & $153.8(71.8)$ & $167.2(113.4)$ & $155.0(67.8)$ \\
\hline & Week 24 & $149.6(104.0)$ & $136.6(76.2)$ & $192.8(165.2)$ & $150.7(71.1)$ & $189.8(141.0)$ & $142.0(74.9)$ \\
\hline \multirow[t]{3}{*}{ Apolipoprotein A1, mg/dL } & Baseline & $159.6(27.8)$ & $160.5(35.4)$ & $152.6(23.2)$ & $158.5(32.7)$ & $158.9(26.2)$ & $159.7(32.8)$ \\
\hline & Week 12 & $159.2(28.1)$ & $162.0(32.8)$ & $154.8(25.3)$ & $164.1(30.3)$ & $157.5(27.9)$ & $167.8(34.2)$ \\
\hline & Week 24 & $163.7(32.1)$ & $161.6(38.0)$ & $150.2(25.7)$ & $163.5(22.5)$ & $161.3(29.8)$ & $167.1(33.4)$ \\
\hline \multirow[t]{3}{*}{ Apolipoprotein B, mg/dL } & Baseline & $91.6(25.5)$ & $86.2(22.2)$ & $106.4(24.1)$ & $79.7(22.3)$ & $101.7(28.4)$ & $86.3(24.5)$ \\
\hline & Week 12 & $89.5(24.7)$ & $84.9(23.8)$ & $107.3(25.6)$ & $79.6(20.7)$ & $95.5(26.3)$ & $85.8(25.9)$ \\
\hline & Week 24 & $91.8(24.2)$ & $88.7(25.0)$ & $91.9(25.3)$ & $83.5(22.9)$ & $95.4(25.2)$ & $91.4(26.9)$ \\
\hline \multirow[t]{3}{*}{ Adiponectin, mg/L } & Baseline & $11.6(6.8)$ & $11.5(8.7)$ & $6.8(3.4)$ & $7.8(3.8)$ & $9.2(4.7)$ & $10.5(8.2)$ \\
\hline & Week 12 & $11.7(7.4)$ & $11.6(8.8)$ & $7.3(3.3)$ & $8.4(4.4)$ & $9.0(4.4)$ & $10.9(9.0)$ \\
\hline & Week 24 & $12.3(7.2)$ & $11.6(9.1)$ & $7.7(3.7)$ & $8.1(4.2)$ & $9.7(4.6)$ & $11.5(9.6)$ \\
\hline \multirow[t]{3}{*}{ Leptin, $\mu \mathrm{g} / \mathrm{L}$} & Baseline & $29.3(20.9)$ & $33.5(28.5)$ & $31.5(23.0)$ & $42.8(36.6)$ & $33.1(17.0)$ & $41.5(30.2)$ \\
\hline & Week 12 & $30.1(22.7)$ & $35.6(30.9)$ & $30.9(29.8)$ & $44.1(31.6)$ & $34.3(18.8)$ & $43.5(32.1)$ \\
\hline & Week 24 & $30.8(22.7)$ & $34.5(28.9)$ & $33.7(25.7)$ & $39.3(25.5)$ & $34.1(22.6)$ & $37.8(22.8)$ \\
\hline \multirow[t]{3}{*}{ Plasma NT-ProBNP, ng/L } & Baseline & $242.0(554.1)$ & $170.1(334.6)$ & $242.1(513.2)$ & $151.0(153.8)$ & $484.0(935.9)$ & $210.8(535.4)$ \\
\hline & Week 12 & $232.2(630.8)$ & $168.2(297.8)$ & $236.8(465.8)$ & $114.4(126.5)$ & $482.8(1116.5)$ & $158.3(266.7)$ \\
\hline & Week 24 & $244.2(687.5)$ & $164.2(315.7)$ & $199.8(382.8)$ & $157.5(229.6)$ & $522.4(1212.0)$ & $174.3(351.1)$ \\
\hline \multirow[t]{3}{*}{ CRP, mg/L } & Baseline & $9.4(16.3)$ & $7.6(11.8)$ & & & & \\
\hline & Week 12 & $8.6(10.8)$ & $4.2(6.2)$ & & & & \\
\hline & Week 24 & $6.2(14.0)$ & $4.3(5.5)$ & & & & \\
\hline
\end{tabular}

$S D$ standard deviation, $P B O$ placebo, $E T N$ etanercept, $I U$ international unit, $H D L$ high-density lipoprotein, $L D L$ low-density lipoprotein, $N T-P r o B N P$ Nterminal pro b-type natriuretic peptide, $C R P$ C-reactive protein

Given this timeline, the time periods evaluated in this manuscript - 12 and 24 weeks - may not have been long enough to capture the long-term effects of etanercept treatment on metabolic risk factors. In addition, the study reported here recruited patients with moderate RA with mean a DAS28 of 4.9, compared with the patients with early RA in the TEAR trial who had mean DAS28 ranging from 5.48 to 5.82 . The lack of high disease activity in this study may have had an 
A Mean value of fasting glucose (mg/dl) by treatment group, visit, and subpopulation

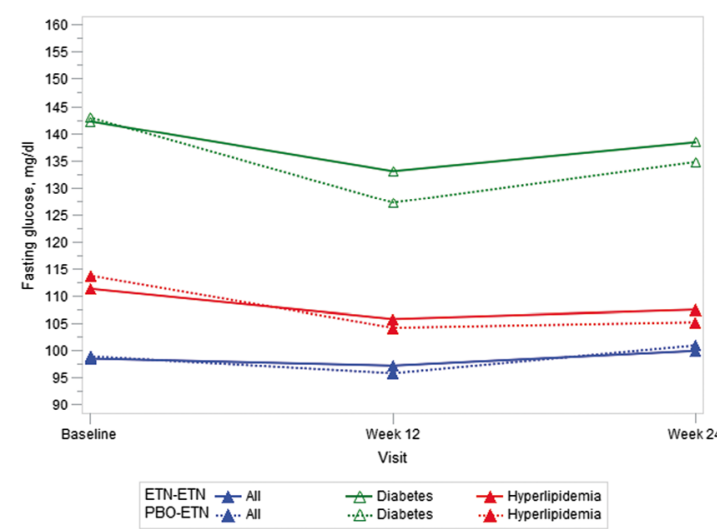

C Mean value of hemoglobin A1C (\%) by treatment group, visit, and subpopulation

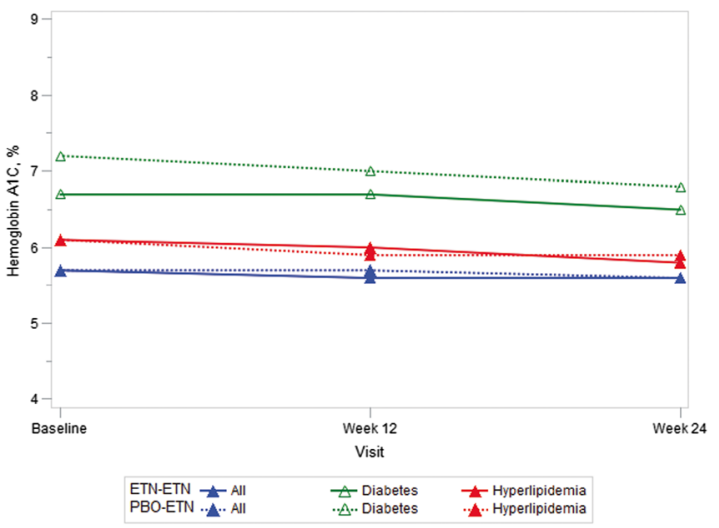

$\mathbf{e}_{\text {Mean value of HDL (mg/dl) by treatment group, visit, and subpopulation }}$

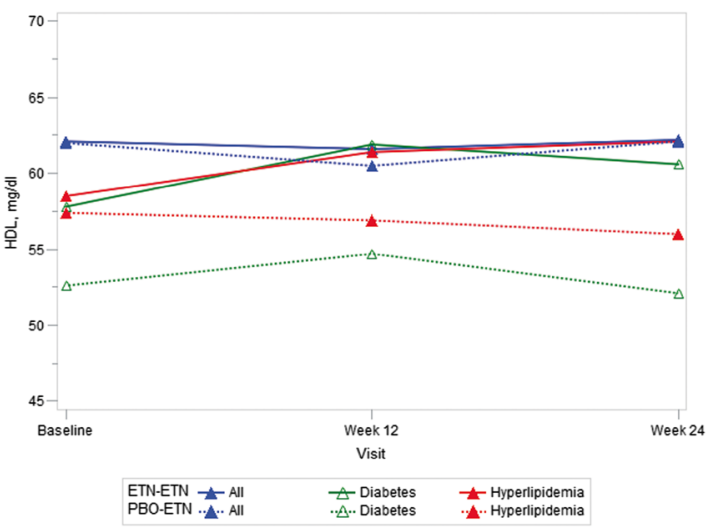

G Mean value of triglycerides (mg/d) by treatment group, visit, and subpopulation

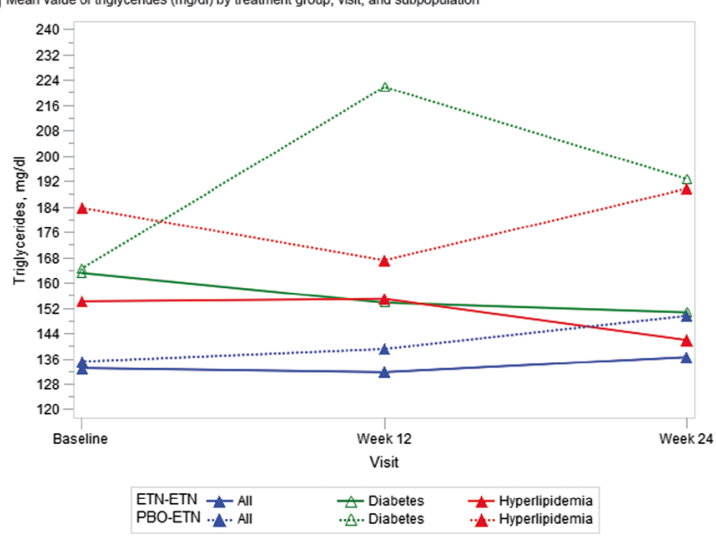

b Mean value of fasting insulin (mIUL) by treatment group, visit, and subpopulation

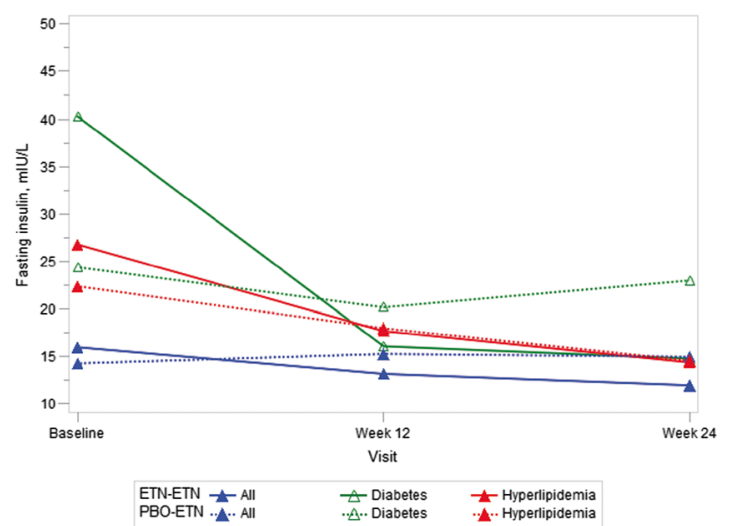

d Mean value of total cholesterol (mg/dl) by treatment group, visit, and subpopulation

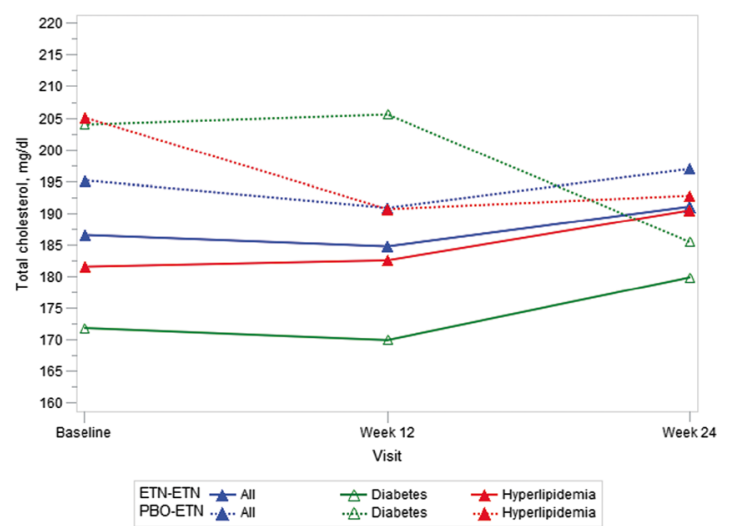

f Mean value of $L D L$ (mg/dl) by treatment group, visit, and subpopulation

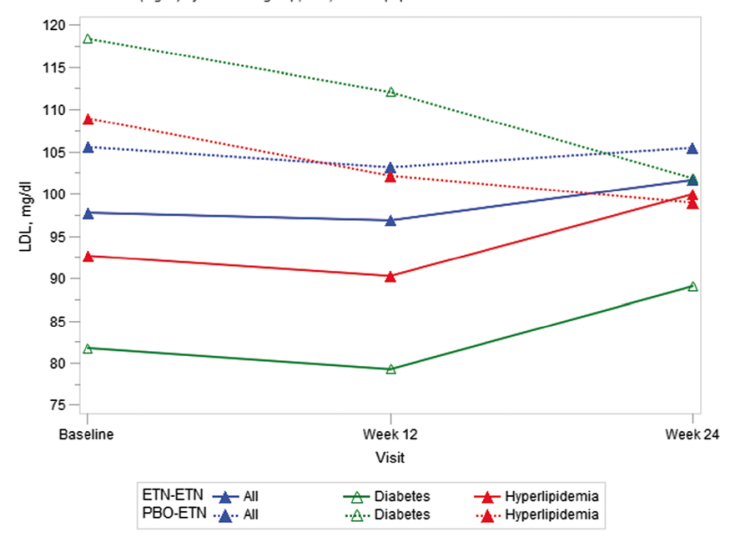


4 Fig. 2 Changes in metabolic analytes from baseline to weeks 12 and 24. Changes in levels of a fasting glucose (mg/dL), b fasting insulin (mIU/L), c hemoglobin A1C (\%), d total cholesterol (mg/dL), e HDL (mg/dL), f LDL $(\mathrm{mg} / \mathrm{dL})$, and $\mathbf{g}$ triglycerides $(\mathrm{mg} / \mathrm{dL})$ in all patients (blue line); patients with diabetes (green line); and patients with hyperlipidemia (red line) who received placebo/etanercept (dotted line) or etanercept/ etanercept (solid line) from baseline to weeks 12 and 24. HDL highdensity lipoprotein, $L D L$ low-density lipoprotein

effect on baseline lipid levels, and the small changes in disease activity in response to treatment with etanercept may have had a lesser impact on metabolic parameters. Another possibility why this study did not show any positive effect of etanercept on traditional CVD risk factors may be that this study was underpowered. Larger studies are required to confirm if this conclusion holds true in different populations.

In managing the CVD risk in patients with RA, it is important to evaluate both traditional CVD risk factors and RA severity. As shown in one study, incorporating both sets of factors into a model enhances its ability to predict the incidence rate of CV events [25]. Furthermore, as described in the European League Against Rheumatism (EULAR) recommendations for CVD risk management in patients with RA, the control of both systemic inflammation and traditional CVD risk factors is important to control CVD risk [26, 27]. The analysis presented here shows that etanercept controls the systemic inflammation in patients with RA, as evidenced by the reduction of CRP, and does not adversely affect levels of traditional cardiovascular risk factors.

Acknowledgments Jessica Ma, $\mathrm{PhD}$ (Amgen Inc.), provided medical writing support.

Compliance with ethical standards This study was approved by the appropriate ethics committee and has therefore been performed in accordance with the ethical standards laid down in the 1964 Declaration of Helsinki and its later amendments.

Funding This study was sponsored by Immunex, a wholly owned subsidiary of Amgen Inc., and by Wyeth, which was acquired by Pfizer in October 2009.

Conflict of interest $\mathrm{AD}$ has received research grants from and served on advisory boards for AbbVie, Amgen Inc., Boehringer Ingelheim, Janssen, Novartis, Pfizer, and UCB. BB is a former employee and shareholder of Amgen Inc. YY and DHC are employees and shareholders of Amgen Inc.

Open Access This article is distributed under the terms of the Creative Commons Attribution 4.0 International License (http:// creativecommons.org/licenses/by/4.0/), which permits unrestricted use, distribution, and reproduction in any medium, provided you give appropriate credit to the original author(s) and the source, provide a link to the Creative Commons license, and indicate if changes were made.

\section{References}

1. Del Rincon I, Williams K, Stern MP, Freeman GL, O’Leary DH, Escalante A (2003) Association between carotid atherosclerosis and markers of inflammation in rheumatoid arthritis patients and healthy subjects. Arthritis Rheum 48:1833-1840

2. Gabriel SE (2008) Cardiovascular morbidity and mortality in rheumatoid arthritis. Am J Med 121:S9-S14

3. Meune C, Touze E, Trinquart L, Allanore Y (2010) High risk of clinical cardiovascular events in rheumatoid arthritis: levels of associations of myocardial infarction and stroke through a systematic review and meta-analysis. Arch Cardiovasc Dis 103:253-261

4. Turesson C, Jarenros A, Jacobsson L (2004) Increased incidence of cardiovascular disease in patients with rheumatoid arthritis: results from a community based study. Ann Rheum Dis 63:952-955

5. Sattar N, McCarey DW, Capell H, McInnes IB (2003) Explaining how "high-grade" systemic inflammation accelerates vascular risk in rheumatoid arthritis. Circulation 108:2957-2963

6. Choy E, Ganeshalingam K, Semb AG, Szekanecz Z, Nurmohamed M (2014) Cardiovascular risk in rheumatoid arthritis: recent advances in the understanding of the pivotal role of inflammation, risk predictors and the impact of treatment. Rheumatology (Oxford) 53:2143-2154

7. Pearson TA, Mensah GA, Alexander RW, Anderson JL, Cannon RO III, Criqui $M$ et al (2003) Markers of inflammation and cardiovascular disease: application to clinical and public health practice: a statement for healthcare professionals from the Centers for Disease Control and Prevention and the American Heart Association. Circulation 107:499-511

8. van Halm VP, Nurmohamed MT, Twisk JW, Dijkmans BA, Voskuyl AE (2006) Disease-modifying antirheumatic drugs are associated with a reduced risk for cardiovascular disease in patients with rheumatoid arthritis: a case control study. Arthritis Res Ther 8:R151

9. Hurlimann D, Forster A, Noll G, Enseleit F, Chenevard R, Distler O et al (2002) Anti-tumor necrosis factor-alpha treatment improves endothelial function in patients with rheumatoid arthritis. Circulation 106:2184-2187

10. Jacobsson LT, Turesson C, Gulfe A, Kapetanovic MC, Petersson IF, Saxne T et al (2005) Treatment with tumor necrosis factor blockers is associated with a lower incidence of first cardiovascular events in patients with rheumatoid arthritis. J Rheumatol 32:1213-1218

11. Hobbs K, Deodhar A, Wang B, Bitman B, Nussbaum J, Chung J et al (2015) Randomized, double-blind, placebo-controlled study to evaluate the efficacy and safety of etanercept in patients with moderately active rheumatoid arthritis despite DMARD therapy. Springerplus 4:113

12. Choy E, Sattar N (2009) Interpreting lipid levels in the context of high-grade inflammatory states with a focus on rheumatoid arthritis: a challenge to conventional cardiovascular risk actions. Ann Rheum Dis 68:460-469

13. Gonzalez-Gay MA, Gonzalez-Juanatey C (2014) Inflammation and lipid profile in rheumatoid arthritis: bridging an apparent paradox. Ann Rheum Dis 73:1281-1283

14. Ridker PM, Cook N (2004) Clinical usefulness of very high and very low levels of C-reactive protein across the full range of Framingham Risk Scores. Circulation 109:1955-1959

15. Daien CI, Duny Y, Barnetche T, Daures JP, Combe B, Morel J (2012) Effect of TNF inhibitors on lipid profile in rheumatoid arthritis: a systematic review with meta-analysis. Ann Rheum Dis 71:862-868

16. Steiner G, Urowitz MB (2009) Lipid profiles in patients with rheumatoid arthritis: mechanisms and the impact of treatment. Semin Arthritis Rheum 38:372-381 
17. Peters MJ, Vis M, van Halm VP, Wolbink GJ, Voskuyl AE, Lems WF et al (2007) Changes in lipid profile during infliximab and corticosteroid treatment in rheumatoid arthritis. Ann Rheum Dis 66:958-961

18. Dixon WG, Watson KD, Lunt M, Hyrich KL, Silman AJ, Symmons DP (2007) Reduction in the incidence of myocardial infarction in patients with rheumatoid arthritis who respond to anti-tumor necrosis factor alpha therapy: results from the British Society for Rheumatology Biologics Register. Arthritis Rheum 56:2905-2912

19. Westlake SL, Colebatch AN, Baird J, Curzen N, Kiely P, Quinn M et al (2011) Tumour necrosis factor antagonists and the risk of cardiovascular disease in patients with rheumatoid arthritis: a systematic literature review. Rheumatology (Oxford) 50:518-531

20. Greenberg JD, Kremer JM, Curtis JR, Hochberg MC, Reed G, Tsao $P$ et al (2011) Tumour necrosis factor antagonist use and associated risk reduction of cardiovascular events among patients with rheumatoid arthritis. Ann Rheum Dis 70:576-582

21. Maki-Petaja KM, Elkhawad M, Cheriyan J, Joshi FR, Ostor AJ, Hall FC et al (2012) Anti-tumor necrosis factor-alpha therapy reduces aortic inflammation and stiffness in patients with rheumatoid arthritis. Circulation 126:2473-2480

22. Maini RN, Taylor PC, Szechinski J, Pavelka K, Broll J, Balint G et al (2006) Double-blind randomized controlled clinical trial of the interleukin-6 receptor antagonist, tocilizumab, in European patients with rheumatoid arthritis who had an incomplete response to methotrexate. Arthritis Rheum 54:2817-2829

23. Schiff MH, Kremer JM, Jahreis A, Vernon E, Isaacs JD, van Vollenhoven RF (2011) Integrated safety in tocilizumab clinical trials. Arthritis Res Ther 13:R141

24. Charles-Schoeman C, Wang X, Lee YY, Shahbazian A, NavarroMillan I, Yang S et al (2016) Association of triple therapy with improvement in cholesterol profiles over two-year follow-up in the treatment of early aggressive rheumatoid arthritis trial. Arthritis Rheumatol 68:577-586

25. Solomon DH, Kremer J, Curtis JR, Hochberg MC, Reed G, Tsao P et al (2010) Explaining the cardiovascular risk associated with rheumatoid arthritis: traditional risk factors versus markers of rheumatoid arthritis severity. Ann Rheum Dis 69:1920-1925

26. Peters MJ, Symmons DP, McCarey D, Dijkmans BA, Nicola P, Kvien TK et al (2010) EULAR evidence-based recommendations for cardiovascular risk management in patients with rheumatoid arthritis and other forms of inflammatory arthritis. Ann Rheum Dis 69:325-331

27. Nurmohamed M (2015) Eular recommendation update on cardiovascular disease in RA. Ann Rheum Dis 74:9 